Advanced BASIC Scientific Subroutines 
Other Macmillan titles of related interest

I. O. Angell Advanced Graphics with the IBM Personal Computer

A. N. Barrett and A. L. Mackay Spatial Structure and the MicrocomputerSelected mathematical techniques

P. E. Gosling Practical BASIC Programming

K. McLuckie and A. Barber Sorting Routines for Microcomputers 


\title{
Advanced BASIC Scientific Subroutines
}

\author{
B. V. Cordingley \\ and \\ D. J. Chamund
}

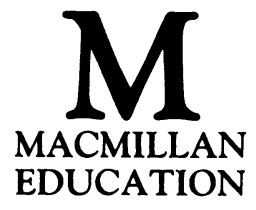


All rights reserved. No reproduction, copy or transmission of this publication may be made without written permission.

No paragraph of this publication may be reproduced, copied or transmitted save with written permission or in accordance with the provisions of the Copyright Act 1956 (as amended), or under the terms of any licence permitting limited copying issued by the Copyright Licensing Agency, 33-4 Alfred Place, London WC1E 7DP.

Any person who does any unauthorised act in relation to this publication may be liable to criminal prosecution and civil claims for damages.

First published 1988

Published by

MACMILLAN EDUCATION LTD

Houndmills, Basingstoke, Hampshire RG21 2XS

and London

Companies and representatives

throughout the world

British Library Cataloguing in Publication Data

Cordingley, B. V.

Advanced BASIC scientific subroutines.

1. Science-Data processing 2. BASIC

(Computer program language).

I. Title II. Chamund, D. J.

502'.8'55133 Q183.9

ISBN 978-0-333-43569-4 ISBN 978-1-349-09282-6 (eBook)

DOI 10.1007/978-1-349-09282-6

Every care has been taken in the writing and testing of the programs contained in this book. It has not been possible, however, to test the programs under all conditions and with the many machines that are available. There will also be interaction between the user's own program and the subroutines taken from this book. Users should therefore satisfy themselves that the operation of the programs and subroutines is suitable for the intended application. No liability for any damage or injury that may result from the use of the material contained in this book can be accepted by the authors or the publishers. 


\section{Contents}

Preface

viii

1 Introduction

1.1 Who Should Use this Book

1.2 BASIC, Style, Structure and Speed 1

1.3 The Subroutines and their Presentation 3

1.4 Syntax, Variables, Statements and Functions 4

$\begin{array}{ll}1.5 \text { Software and Rounding Errors } & 6\end{array}$

1.6 How to Use this Book 8

2 The Subroutines 9

2.1 Generation of Random Numbers 9

RNDBIN - Binomial random number generation 9

RNDPSN - Poisson random number generation 12

RNDNRM - Normal random number generation $\quad 15$

RNDEXP - Exponential random number generation 18

2.2 Probability, Density and Distribution Functions 20

BINOPD - Binomial probability and distribution function 20

POISPD - Poisson probability and distribution function 22

NORMDT - Area under the normal curve 25

XPONDD - Exponential density and distribution function 29

LNGAMM - Natural logarithm of the complete gamma function 31

GAMMFN - Ratio of the incomplete gamma function 34

BETAFN - Ratio of the incomplete beta function 37

CHISQD - Area under the chi-squared curve 42

FDISTR - Area under the F-curve 45

TDISTR - Area under Student's $t$ curve $\quad 47$

$\begin{array}{ll}2.3 \text { General Statistics } & 50\end{array}$

$\begin{array}{ll}\text { MNVRNC - Mean and variance } & 50\end{array}$

MAXMIN - $\begin{aligned} & \text { Sorting data, percentiles and cumulative frequency } \\ & \text { distribution }\end{aligned} 53$

COMMNS $-t$ method of comparing the difference between two means for paired and unpaired data 58

CONTIN $-m \times n$ contingency table with chi-squared test 64

PERCOM - Factorials, permutations and combinations 69 
2.4 Analysis of Variance $\quad 72$

OWAOVA - One-way analysis of variance $\quad 72$

TWAOVA - Two-way analysis of variance with and without replicates $\quad 77$

$\begin{array}{ll}2.5 \text { Linear Regression } & 87\end{array}$

MLNRG1 - Summary statistics for regression 87

MLNRG2 - Determines values for the regression coefficients 87

$\begin{array}{ll}\text { MLNRG3 - Regression ANOVA table } & 87\end{array}$

MLNRG4 - Analysis of residuals $\quad 87$

POLYRG - Polynomial and other linear regression 100

$\begin{array}{ll}2.6 \text { Matrix Operations } & 104\end{array}$

MATADD - Matrix addition 104

MATSBT - Matrix subtraction 104

MATTRN - Matrix transposition 104

MATCNT - Matrix multiplication by a constant 104

$\begin{array}{ll}\text { MATMUL - Multiplication of two matrices } & 104\end{array}$

MATRED - Reads a matrix from a DATA statement 104

$\begin{array}{ll}\text { MATWRT - Prints a matrix } & 104\end{array}$

MATEGN - Computes eigenvalues and eigenvectors of a real

MATINV - Inverts a matrix 119

MATDET - Finds the determinant of a matrix 119

2.7 Interpolation $\quad 125$

INTPLN - Interpolation by the Lagrange polynomial method 125

$\begin{array}{ll}2.8 \text { Numerical Analysis } & 128\end{array}$

CHBSHV - Generates a Chebyshev polynomial 128

FURIER - Fourier series used to approximate observed periodic data 133

$\begin{array}{ll}2.9 \text { Calculus } & 138\end{array}$

DIFEQ1 - Numerical solution of a 1st-order differential equation 138

DIFEQ2 - Numerical solution of a 2nd-order differential equation 138

TRPZDL - Numerical integration of a function by the trapezium rule 145

SIMPSN - Numerical integration of a function by Simpson's rule 145

INTDAT - Integration of numerical data by Simpson's rule 145

$\begin{array}{ll}2.10 \text { Solution of Equations } & 151\end{array}$

SOLUTN - Analytical solution of a system of $N$ linear equations with $N$ unknowns 151

QADEQN - Finds the two roots of a quadratic equation by an analytical technique

CUBEQN - Finds the three roots of a cubic equation by an analytical technique

NEWITR - Numerical solution of an equation by Newton's method

BISECT - Numerical solution of an equation by the method of bisection 
2.11 Complex Numbers

COMPLX - Performs addition, subtraction, multiplication and division of two complex numbers. Finds the reciprocal, square, polar and non-polar forms of a single complex number

References

Index 


\section{Preface}

The use of computers today for scientific and engineering purposes is commonplace. School pupils studying science-based subjects will almost certainly have had some hands-on experience of computing by the time they are ready to sit their final examinations. Those leaving university with a science or engineering degree are likely to have a working knowledge of more than one high-level language.

In the mid 1960s computer programming was just beginning to feature in the syllabuses of some undergraduate courses. The emphasis on programming at that time was to save memory, increase speed and if possible make the program code understandable to the author and perhaps even other users. Advances in microelectronics have today made possible the production of machines of such memory capacity and speed that under many conditions of use, memory space limitations and computing time place little constraint on the programmer. The current emphasis is on structure and style of programming.

What has not changed so dramatically is the effort required to design and develop computer software, and this is reflected in the changes in the relative costs of software and hardware over the same interval. Every machine requires software to drive it, and for large jobs or tasks of a specialist nature there is probably no real alternative to the purchase of commercial software or its production by those highly proficient in this task. Commercial software, however well written, is likely to suffer from several limitations: it is first of all expensive; it tends to be machine specific and so can suffer from limited portability and is often accompanied by copyright restrictions; it is rigid and not generally amenable to modification by the user and input and output are predetermined. The software, to obtain wider marketability, is often far more powerful and consequently complex than the user requires. If it has to be purchased, then the right type of software has to be found and studied - all points that make it difficult to justify for those smaller jobs. It is these and other limitations that contribute towards the reasons why many engineers and scientists write some software themselves - the need to do this is implicitly recognised by the proportion of time devoted to this task in the formal training that they currently receive.

What we have attempted to do in this book is to provide a collection of subroutines which can function as the building blocks for scientific programs of the user's own creation. We have written them in a uniform style and presented them in a manner which we anticipate will make them easy to use. BASIC has been 
selected as we believe it is the language with which potential readers are still most likely to be familiar and the one that will be compatible with their computer both at home and in the workplace.

One of the problems encountered in compiling a book of this nature is to know what material to include and what to exclude. Subroutines which would be relevant but which only occupy a few lines of code and which also are likely to cause no problem to the user have been omitted, as have those which would be regarded as trivial by the anticipated readership. Other work has had to be eliminated through restrictions on space, or because it was thought to be too narrow in its application. We have attempted to retain only what we consider to be the most generally useful material.

In the preparation of this book, help has been received from several sources. Here we should like to acknowledge with gratitude the assistance of Michael $\mathbf{J}$. Morris of the School of Economic and Social Studies, University of East Anglia; Martin Wilson of the Department of Statistics and Operational Research, Coventry Polytechnic, for assistance with the details of some of the statistical subroutines; and Juliet Davison for her help in kindly typing the manuscript. 